\title{
Not for Profit Board of Directors: Getting Organized A Qualitative Study of Chambers of Commerce Governance
}

\author{
Robert Rohrlack \\ University of South Florida
}

This study looks at the complicated relationship between a volunteer board of directors and the best governance solutions to have the organization operate smoothly. By identifying the experiences of the chamber of commerce executives, this study identifies five recommendations for organizing a board of directors for best governance. The study also identifies best practices for selecting board members to serve to increase volunteer commitment and reduce potential conflict among members. This study is informative for any not-for-profit or non-profit organization seeking to organize better and allow the board to focus on the mission of the organization for greater success.

\section{INTRODUCTION}

There are over 7,000 chambers of commerce in the United States at the end of 2017, according to the Association of Chamber of Commerce Executives (ACCE), the premier organization for chamber of commerce professionals. A chamber of commerce in the United States is a voluntary membership organization that relies on businesses joining the organization for the benefits offered and the networking opportunities to grow their business. Each chamber of commerce is a separate, independent organization. Each chamber will self-determine how they are governed and operate. Typically, a chamber of commerce will be funded by membership dues and through events for members to network and learn best business practices. The typical role of a chamber of commerce is to be a hub organization for businesses to join for common issues and network their business for growth.

The governing body of chambers of commerce in the United States has a variety of board structure types. It is often called a board of directors but, the governing body can have a variety of names. (board of trustees, the board of governors, the board of advisors, the board of directors). There is not a required structure for this board beyond fiduciary requirements and responsibilities. Due to no formal or informal criteria for chamber board design, comparing one organizational structure to another is difficult. The structure and mix of board members for one organization may work for that organization but may not for another organization. It cannot be assumed that what works for one organization will work for the other. There is a wide range for board size of a chamber of commerce. ACCE tracks chambers on a variety of measurements. One of the criteria is the number of members on the board. According to ACCE, the membership ranges from 16 to over 140 members of a chamber board. Table 1 below illustrates the average board size distribution of chambers of commerce in the United States. (ACCE 2018). The preference of the specific chamber dictates the acceptable size. 


\section{TABLE 1 \\ CHAMBER OF COMMERCE BOARD OF DIRECTORS SIZE}

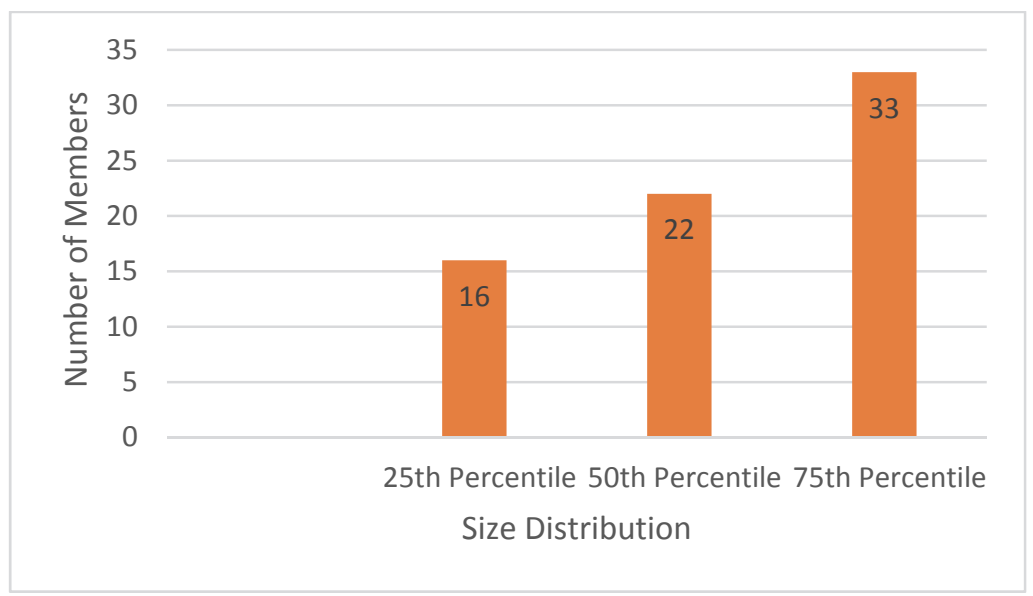

Chart 1: ACCE Dynamic Benchmarking Tool 2018

All chambers of commerce have governing boards that consist mostly of volunteer members who bring their business perspective to the governing role of the organization. It is common for the President to also sit on the board without voting privileges. The author's purpose was to examine how not-for-profit organizations structure the board of directors by reviewing four separate chambers of commerce board of directors in the same geographic region. Additionally, the author wanted to learn how the chamber of commerce President views the structure and if they had the opportunity, what would occur if they designed their board of directors versus what they had to accept working with a voluntary board of directors.

\section{REVIEW OF LITERATURE}

Scholarly work is abundant in general on the board of directors' duties. Most of this literature focuses on for-profit businesses or non-profit organizations, typically social service organizations. However, there is little scholarly research about a chamber of commerce in the United States. Most scholarly information available is concentrated in chambers of commerce in Europe, specifically about chambers of commerce in the United Kingdom (Bennett 1995, 1996, 1997, Fraiser 1973).

There was an extensive search conducted to find information specifically about chambers of commerce in the United States. Chambers of commerce in the United States are designed and governed differently than in other countries. Therefore; literature searches specifically targeted to U.S. chambers was conducted. Chamber boards, the structure of governance of the chamber, and guidelines for chamber board design were topics for the search. The research identified focused on the process of having an active board and having an accountable board of directors, (Stephens, Dawley, Stephens 2005). This research did not investigate how to determine the size of the board or how to create and fill openings on a board. Research specifically on chambers of commerce, the board size, and design is lacking.

Of the limited and relevant data available, most is dated. Some of the most pointed and direct research about chambers of commerce dates back several decades to the 1920s. One dated article discussed the role of a chamber to bridge economic cohesion among different socio-economic groups for the benefit of the community (Brown 1922). Although the article is almost 100 years old, an argument could be made that it is relevant for the current political and economic application. Most of the research discusses the level of influence and the ability to be the leading driver for the economy (Schultz and Blumberg1957). The relatively current research tends to focus on the chambers of commerce in Great Britain and Ireland. 
There is also the phenomenon of the different chambers of commerce's that are "Public Law" or "Private Law." The Public Law chambers refer to chambers of commerce typically found outside of the United States. They are financed by businesses that are required to join. It is like a tax on companies (Public Law). In the United States, a chamber of commerce has a voluntary membership (Private Law). The inherent conflict of these two types of chambers is inherent in the countries with a combined system but is unknown in the U.S. (Miller 1958).

The focus of his study was how each type of chamber works to influence power in their community. This comparison did not discuss board structure.

How policy develops for government advocacy department in a chamber and how it changes over time was studied by (Crawford 2015). He studied how organizations merge differing views to determine the positions and actions of organizations. The example of American chambers of commerce, specifically the U.S. Chamber of Commerce and the Michigan State Chamber of Commerce are studied. Most often, state and national chambers are primarily political advocacy organizations that work to influence legislation impacting business and commerce in their service territory. Crawford studied how their work can be polarizing or be seen in cooperation, depending on the issue and how it is communicated. The chamber influencing policy in its service area was analyzed as well as the elements that cause the organization to adapt and change the positions of the organization.

The analysis of organizational commitment by volunteer members and how it compared to the paid staff commitment is studied for the cultural elements of the organization by (Dawley, Stephens, and Stephens 2004). They have several articles on chambers and their role in the community. Their work has typically focused on a type of influence external to the chamber. Similarly, (Barnes 1924) discussed the industry development in a city and the role a chamber of commerce plays in the effort to attract business. Barnes' focus is on the demands of a chamber of commerce to improve the distribution of goods coming to a community and products being distributed out of the community to impact commerce. These demands, according to Barnes, have many interests and a chamber of commerce cannot respond to all. How the chamber can play varying roles, depending on the community interest in industrial development, is discussed in Barnes analysis.

In an area geographically like this study, (Noel and Luckett 2013) explored a chamber in Southwest Florida that was within 50 miles $(80 \mathrm{Km})$ of the chambers interviewed for this paper. The focus of their work was to identify motivating factors to a small business joining their local chamber of commerce. Their analysis concluded that four primary elements (reputation building, corporate responsibility, business development, and networking and growing contacts) were the primary reason a small business joins their local chamber.

Continued research for studies and articles for this research was conducted. The results produced varying research on business that did not match the focus of this study. Many items focused on a different business topic and used a chamber of commerce as one example. When the chamber of commerce was the topic of study, the specific review of a chamber board design was not the focus of the research.

\section{Method}

For this study, four chambers of commerce were identified for examination. Each of the chambers serves a market within a larger metropolitan area in Florida. They have a generally accepted service territory and primarily focus on retail businesses for membership. The four chambers have a board of directors and an executive committee. These two volunteer groups at each chamber serve as the governing system for the chamber. The chambers were chosen for their strong support in their market and the relative proximity to one another.

The experience of each President was long enough for them to have established themselves as the leaders the senior staff person for the organization. Table 2 below illustrates the service area of each chamber President interviewed and the tenure of each President in their position. 


\section{TABLE 2 CHAMBER OF COMMERCE PRESIDENTS INTERVIEWED}

\begin{tabular}{|c|c|c|}
\hline $\begin{array}{l}\text { Chamber of } \\
\text { Commerce }\end{array}$ & $\begin{array}{l}\text { President } \\
\text { Tenure }\end{array}$ & Service Area \\
\hline A & 5 & Sub-city region \\
\hline B & 4 & town \\
\hline C & 10 & county sub-market \\
\hline D & 6 & county sub-market \\
\hline
\end{tabular}

Chart 2: Chamber CEO service territory and tenure in current position

Their separate interviews were conducted with each chamber of commerce President to gain insight into their board of directors design and the strategy used in the determination of the board composition. The first interview was to examine the chamber and the role the President and CEO served to structure the board. Three of those interviewed had experience in the board structure development and by-laws design. In addition to the two separate interviews of each President, each chamber's by-laws were studied for design structure and authority responsibility delegation.

Once the first in-person interviews were conducted, one of the chamber Presidents was eliminated from further research due to their short tenue on the job; there was a focus on three remaining chamber Presidents to go into more detail on the experience of forming the board of directors structure. The initial in-person interviews of each chamber President took place in April 2018. Subsequent phone interviews were conducted in August 2018. The discussions focused on the structure of the board of directors and how the organization focused its strategy to create the process they use to govern the organization. Additionally, how the chamber President viewed the process was discussed.

There were strong opinions on the importance that the organization must have a secure check and balance system in place that can keep the authority of the governing body from having excessive control. However, when a merger discussion revealed by one chamber President was identified, a third interview, became relevant to the experience of the two mergers became the focus of this study.

One of the four chambers had gone through a merger of two chambers within the past 18 months. Additionally, they had just completed a second merger with a third chamber, resulting in three chambers of commerce becoming one in less than 18 months. These were two different experiences with varied reactions from each merger. The mergers proved to be relevant for providing information on the chamber board of directors governance. Each involved a decision process for determining how a governing board would be established to incorporate the new membership. This phenomenon provided an enhanced and more compelling study. The back to back reorganization of the board gave insight into how the board identified its rationale for governing a new chamber of commerce and is discussed in the results section.

\section{RESEARCH DESIGN}

The interviews and by-laws review proved to be useful information for the study. The first interview was to establish which chamber and President were appropriate for the study. This step was used to identify the viability of utilizing each chamber for this study. Chamber $\mathrm{C}$, due to the lack of history of the President with the organization, was eliminated. The by-laws at Chamber $\mathrm{C}$ were designed before the President started with the organization. The chamber President did not know the decision-making process that was used to develop the by-laws. Because of this lack of knowledge, this chamber was eliminated from the study. 
Three chambers of commerce Presidents were used to examine why the organization's governing body is designed in its current structure and how the Presidents feel about this structure. The second interview was recorded using the recording and transcription software. Rev is a mobile phone-based application that can record phone calls. There is an option to have the calls transcribed within a brief period. Rev was used for transcribing the interviews. The interviews of the three chamber Presidents were conducted relatively close together in time. The transcriptions were coded to identify consistent topics that had not been impacted by remarkable events that could have occurred between interviews. The coding identified some common themes for the board of directors' development. The experience of Chamber D was exciting due to the recent experience of two mergers with other chambers. This disruptive growth provides an opportunity for strength but also brings an opportunity for problems.

This study is a phenomenological study that studies three chambers of commerce Presidents and CEO's and their role and interpretation of their board of governors' design. The experience that Chamber $\mathrm{D}$ went through with two mergers prompted a third interview. It was the second interview recorded and transcribed with that President for a total of four recorded and transcribed interviews. This study looks at the shared experiences of three chamber of commerce Presidents to understand their boards. According to Creswell and Poth (2018) this type of research, "describes the common meaning for several individuals of their lived experiences of a concept or a phenomenon." This type of research focuses on the commonality that the participants share in the lived experience. Chamber of commerce Presidents experience working with their board of directors is the shared experience studied.

Each year a chamber of commerce has a new chairman who brings their ideas and desires for the organization. The President and CEO is the consistent factor for the organization guiding the chamber toward the long-term goals established by the board and consistent with the strategic plan. The board design and structure will enable the chamber to succeed or will slow the progress down.

\section{Results}

When analyzing and coding the chamber President's interviews, they were divided into the separate topics discussed during each interview. Once each interview was coded by topic, themes emerged among the three interviews. These initial themes were confirmed by reviewing the common situations among those interviewed. The chamber Presidents had similar experiences and reacted to the experiences in similar ways without any collaboration between them. Each chamber had gone through a process to establish their governing board of directors. While there is no generally accepted style or format for board structure or design, there tend to be some shared experiences that these chambers of commerce realized.

\section{Theme 1: Change Takes Time}

Each chamber President expressed the need to be patient to make the changes they desired with their board. Chamber A President expressed it as, "We've had a lot of changes over the past four years, and sometimes I look at it, and I think, 'Wow, four years went by really fast,' and other times I look at it, and I think like, 'Wow, it's been a really long four years." Chamber A President expressed the need to prove to the board that they can trust the President and allow the person to do the job. Chamber A President felt there had been experiences micro-management. The previous President who served before President A did not have signature authority for check signing. Only volunteer officers could pay the bills. When Chamber A President arrived, the focus was to work hard to change this practice and have more authority. Over time the volunteers saw the better way to manage the organization and granted the authority.

Chamber D President also pointed out the need to allow time to make the changes desired for the board. The President's strategy took six years to implement. The volunteers of the chamber required a comfort level and trust each other before taking organization change. Then they needed to be confident with the President to allow for the authority to shift to staff. Chamber President D patiently worked to build trust with each Chairman over the years and gained the power needed. Chamber President D stressed the need to make sure the leadership was informed of what was taking place at the organization and seek their input on critical decisions. The team approach helped gain trust for the President. 
Chamber B President reinforced the need to make the changes for an active board over time and not have changes be too dramatic to shock the board. The President stressed that the process was a mutually beneficial experience. Over three years, this President worked with each chair to assure them that the need for the President to be successful was interdependent on the Chairman being successful as well. As he kept reinforcing this over the three years, trust grew, and the board became comfortable following the President's leadership.

\section{Theme 2: Determining the Right Size is not an Obvious Process or Perfect Science}

Each chamber President had difficulty identifying a specific appropriate size for their board. They used statements like, "... struggled to pick..."; "...had an arbitrary formula..." "...what we have seems to work for us now..." when discussing their board size.

Chamber D President was confident that the board was the right size, "for now." With two mergers completed, they had to make decisions to accommodate the joining entity each time. With each merger, they would add board seats that had a unique, specific time limit to them. The new chamber representatives agreed at the beginning when the added terms would expire from the board. The abbreviated time board seat was agreed to with each merger ahead of time.

At one point in the process, Chamber D President had developed a formula to determine how many board members to have based on the number of actual members in the chamber. As the chamber merged with one chamber then combined with one additional chamber, the formula proved to be unsustainable as the board would have grown exponentially. Additionally, as the mergers occurred, it was discovered that the number of members reported by the merging chamber proved to be inflated compared to the number of actual paying members. Having to go back and reduce the board based on the actual lower number of members would be awkward and was quickly discontinued.

Chamber A had reduced their board from 21 members to 15 members when they re-wrote their bylaws. There was agreement that this was the right decision. However, after implementing the decision and living with it for a few years, some grew to believe that the reduction was too impactful and restrictive. Chamber A President stated that the chamber was concerned they would, "lose potential great leaders that, because they're not gonna [sic] be given the opportunity with our organization, they might find an opportunity somewhere else because we've limited our board to such a small number." The President added that there was a feeling of having to adjust to the situation. There was a natural aversion to changing the by-laws every time there was something someone did not like. Any change to the board size would require a by-laws update. This conflict of ideas would have a restrictive impact on the organization's ability to adjust when needed.

\section{Theme 3: Elimination of Elections for Board Members}

All chamber Presidents interviewed agreed that having elections for board members was a problem. There was a stigma to the act of a public vote of board members. Fear of not being selected and having to face a loss in public among business peers kept many potential board members from being willing to get involved according to Chamber A President. The President claimed that people said they wanted to be on the board but did not want to face a "popularity" contest to be elected. "It felt sophomoric to them, very high school."

Chamber B President used personal experience serving on boards of other organizations to explain the aversion to electing board members. "I serve on a lot of different boards, and I have never in my life had to run for election to a board; its' always been something that I have been approached, I have been nominated [to serve].

Chamber B President also mentioned that they would proactively recruit chamber members to run for the board seats becoming available and would get turned down. The person nominated did not want it to be a popularity contest for board selection and would be concerned about how that would reflect on their business. The chamber was promoting a "winners and losers" competition, according to the Chamber President B, "It was terrible!". This chamber took the awkward process one step further. They would nominate at least two board members for the Chairman position. There would be a public election; one 
would win, one would lose. Then, you had someone who lost sitting on the board as a board member and unhappy. "It caused some difficult issues."

Elections had various forms. Some had been an application process to be placed on a ballot for the members to vote. Some had been a slate chosen by the board and the general membership voting for a limited number of candidates to fill vacancies. No matter the method, having elections was unpopular with the members at large and tended to keep the most desirable candidates away from serving, according to all Presidents interviewed.

Each of the chamber Presidents interviewed stated that they had moved from election of members to a nominating committee selecting the slate for board openings. They started to use a more structured nominating committee process. There is a separate nominating committee that is responsible for proposing a slate of directors to serve on the board. Their job is to select the best-qualified candidates that can help while keeping in mind the need to have a representative board of the industries in the community and having a diverse board that is also reflective of the city. It is more complicated but spares people's feelings as there is a private, confidential discussion by the nominating committee rather than public voting. The by-laws describe how to select who serves on the nominating committee to prevent any problems of favoritism. All the chamber Presidents interviewed stated that the nominating committee process resulted in a stronger board as more people were willing to serve on the board for their chamber.

\section{Theme 4: Use an Outside Consultant for Reorganization}

When each chamber was taking significant steps to restructure their board, in hindsight, each Chamber President agreed it would have been better to bring in an outside consultant to help make objective decisions and eliminate the personal politics. The two mergers of Chamber D best illustrate this theme. When the first merger took place, one of the chambers was in the process of closing. The struggling chamber did not want to have the chamber cease to exist. The desire to keep a chamber of commerce in the area prompted them to go to Chamber D and suggest a complete merger, which was a takeover when completed. The failing chamber turned over all their assets, member roster, property, and name to Chamber D. The acquiring chamber had complete control and decision-making authority. They absorbed the members from the failing chamber and eliminated any duplicates on the role and expanded their territory. They allowed several members from the failing chamber to join the board for six months. Any member who was not a member already at Chamber D was given six months membership to assist in the transition and would need to pay to be a member after the six months had passed. The process was smooth and went well. It was not the same experience in the second merger.

There was significant separation of merging strategy between the two chambers in the second merger. Chamber D had a position of being in charge as they started the discussions. There was a sense of control and authority since they had just completed a smooth merger. The other chamber in the second merger negotiations had just walked away from an attempted merger that failed with a different chamber. There was a defensiveness at this chamber, and they felt Chamber D was not treating them fairly and did not value them correctly. Due to a lack of agreement, there was considerable debate and hurt feelings in the process. Chamber D President admitted that focus on the issue was lost and was more committed to looking strong personally and be the President who had done two mergers and was now the largest chamber in the county. "Some of my committee members got very caught up in almost like, "ha, ha, ha, look what we did.' We made it happen. [The failed merger chamber] couldn't (sic) make it happen"'. "For me as CEO, it was a very strategic move."

Looking back, Chamber D President felt it would have been better to bring in an outside consultant to analyze and give advice on the merger. Chamber D President believed firmly that, with the external analysis, they would have walked away from the second merger. The investigation after the fact would be discovered the problem before the merger. They would have realized the chamber was overstating their position and they desperately needed to merge. In hindsight, Chamber D President believed it would have been better to let them fail and then go in and clean up the collapse in the service territory with the stronger resources of Chamber D. "We should have asked more questions on why are you in a hurry to get this done? And then I think I mentioned in the first interview that I would've had a full audit. We 
would've gone through (sic) the expense and had a full audit and then come back with what the demands are to complete the merger. Perhaps even consulted with an acquisition consultant to help go through the valuation process before merging." The role of the consultant would have helped analyze information objectively and take the emotion out of the discussion. That would have allowed the two chambers in the merger to leave an opinion and feeling out of the equation and focus on the facts of the situation.

As Chamber D worked on developing a new strategic plan for the twice merged chamber, a consultant was brought on board to assist with the development of the project. "That is why I want [the consultant] even more, because, she was able to say "no, this is the role of the board. This is the role of the management of the organization. The board is not managing the organization." The consultant was saying this to the chair of Chamber D.

A consultant can work with the President to prepare for the meetings and then be present as the subject matter expert. They will help guide the President toward the goal they have set. They will step in and deal with difficult people who are causing the process to slow down. A qualified consultant will get you to the goals set before the meeting.

\section{Theme 5: Robert's Rules of Order}

Each chamber President agreed that it was critical to their success to be governed with standard rules for running a meeting, specifically by Robert's Rule of Order. This guide is the most widely used book for parliamentary procedure in the United States. It sets rules for meeting governance and the process to run a meeting and have an orderly debate on issues before a governing body. Chamber B pointed out that they had, "...tweaked the by-laws to where they aligned with Robert's Rules." Having an objective set of rules in place before any potential conflict or tension develops was essential to keep matters from becoming personal. Chamber B President added, "We have a chamber attorney...they set everything up to where it aligned with Robert's Rules. We were missing a few things".

To be governed by Robert's Rules of Order correctly, it is stated in the by-laws of an organization. Of the four chamber Presidents initially interviewed in person and the three that were interviewed and recorded, all mention that Robert's Rules of Order was mentioned in their by-laws and their governing authority. Typically, Robert's Rules of Order are referred to in a separate article in the by-laws as "Parliamentary Authority" as in Chamber A's and Chamber D's by-laws and as "Parliamentary Procedure" in Chamber B's by-laws. (Chamber C refers to Robert's Rules of Order in their by-laws as "Parliamentary Authority").

By mentioning Robert's Rules of Order in the by-laws, there are two benefits. First, the board voted to approve the by-laws and the mention of how they would conduct their meetings by allowing the mention of Robert's Rules of Order to be in the document. They are agreeing to follow Robert's Rules for their meetings by voting yes on the by-laws. This action is essential for the second purpose. If a controversial issue arises at a board meeting and the session becomes tense, Robert's Rules of Order sets the stage for debate and decision. It was pre-approved by the body and will be in effect for the discussion. Having Robert's Rules of Order in the by-laws is a safety measure for the chamber that allows for full discussion but prevents one opinion from over running the meeting.

Board members can be wary of formalizing the use of these Parliamentary Procedures guidelines. They tend to be concerned that they will turn the meetings into formal, stuffy events that prevent open discussion. Most often when it stated that Robert's Rules of Order are in the by-laws, members understand that it works like an insurance policy. Until it is needed, there is a tendency to forget it is in the by-laws. However, when needed, they have the process in place to run the meeting. When a meeting or discussion starts to become unorganized or disruptive, it is too late to get approval to govern by Robert's Rules of Order. That needs to be done earlier in the process. 


\section{FUTURE RESEARCH}

Chambers of commerce are unique organizations in a community. They are purposefully designed to have a diversity of members working together to improve the community they serve. This type of research is different from a professional association that focuses on one industry for membership. Currently, there is little scientific research on chambers to help them in their development and strategic planning. The chamber Presidents interviewed shared experience with their board and input to their plans is insightful for Presidents considering how to design their boards or re-write their by-laws. This experience is useful and applicable to chambers of commerce or any not-for-profit or non-profit business membership-based organization.

Future research on best practices can be valuable as chambers tend to "figure it out as they go" as was stated by Chamber A President. Chambers are dealing with many changes in their economy. They are working to meet the demands of a changing work environment and be relevant to their community. The members in general and the members who serve on the board of directors want to be impactful and help the organization move forward but can have numerous methods to get it accomplished. With a chamber of commerce chairman typically changing every twelve months, the President of the chamber becomes an essential player in the success of the organization. It is critical for the President to establish themselves as a confident and trustful leader.

With the lack of scholarly research available on the chamber of commerce industry, the research field has ample opportunity to explore topics related explicitly to the chamber of commerce. There is an extensive research area concerning issues of membership value and service delivery of chambers of commerce. With the economy going through significant changes, the study of how a chamber can stay useful presents many research topics to explore. The research can result in stronger chambers with a more impactful result for the community they serve.

The structure of the board is also a crucial factor for the chamber's success. The governing body plays a vital role in the organization. Each of the chamber Presidents interviewed discussed the importance of the board being designed to be a working body and work well with them. With no research identified that addresses this specific topic, research in this area could be valuable to the chamber of commerce industry. There are a wide variety of research topics related to chamber boards size and structure, chamber boards relationships with their President, and how the President fulfills his or her role for the chamber to succeed. With chamber boards acceptance of objective guidelines, as demonstrated by the by-laws, studies on best practices for chamber operations will be useful to the industry professionals and the volunteers that serve on the boards at the over 7,000 chambers of commerce throughout the United States. 


\section{REFERENCES}

Acce.org/about/chamber-of-commerce. (2018). ACCE $\mid A C C E$. Retrieved September 30, 2018, from, http://www.acce.org/

ACCE (2018). Retrieved from http://www.acce.org/research/dynamic-chamber-benchmarking/

Barnes, J. H. (1924). Modern Distribution Demands upon the Chamber of Commerce. The Annals of the American Academy of Political and Social Science, 115, 136-141.

Bennett, R. J. (1998). Explaining the Membership of Voluntary Local Business Associations: The example of British Chambers of Commerce. Regional Studies, 32(6), 503-514.

Bennett, R. J. (1995). The Logic of Local Business Associations: An Analysis of Voluntary Chambers of Commerce. Journal of Public Policy, 15(3), 251-279. Retrieved August 29, 2017.

Brown, A. (1922). What the Chamber of Commerce Can Do in Promoting Better Industrial Relations in a Community. Proceedings of the Academy of Political Science in the City of New York, 9(4), 210217.

Chambers of Commerce: The Basics. (2009). Chamber Basic Primer, V, 1-6. Retrieved September 13, 2017.

Crawford, B. (2015). The historical and cultural construction of legitimated interests: the rise of American Chambers of Commerce. Management \& Organizational History, 10(3-4), 229-249. Retrieved April 29, 2017.

Creswell, J., \& Poth, C. (2018). Qualitative inquiry and research design, $4^{\text {th }}$ ed. Los Angeles, CA: Sage, p. 75.

Dawley, D. D., Stephens, R. D., \& Stephens, D. B. (2005). Dimensionality of organizational commitment in volunteer workers: Chamber of Commerce board members and role fulfillment. Journal of Vocational Behavior, 67, 511-525. Retrieved September 13, 2017.

Fraiser, T. C. (1973). Chambers of Commerce and the Trade Associations. Journal of the Royal Society of Arts, 121(5208), 788-798. Retrieved September 12, 2017.

McCullough, E. W. (1928). The Relation of Chamber of Commerce of the United States of America to the Growth of the Simplification Program in American Industry. The Annals of the American Academy of Political and Social Science,137(May), 9-12. Retrieved September 13, 2017.

Miller, D. C. (1958). Decision Making Cliques in Community Power Structures: A Comparative Study of an American and English City. American Journal of Sociology, 64(3), 299-310. Retrieved April 26, 2017.

Schultze, R. O., \& Blumberg, L. U. (1957). The Determination of Local Power Elites. American Journal of Sociology, 63(3), 290-296. Retrieved August 26, 2017.

Schulze, R. O. (1958). The Role of Economic Dominants in Community Power Structures. American Sociological Review, 23(1), 3-9. Retrieved April 26, 2017.

Stephens, R. D., Dawley, D. W., \& Stephens, D. B. (2004). Commitment on the Board: A Model of Volunteer Directors' Level of Organizational Commitment and Self-reported Performance. Journal of Managerial Issues, 16(4), 483-504. Retrieved August 14, 2017.

Tan, T. W. (1986). Voluntary Associations as a Model of Social Change. Southeast Asian Journal of Social Science, 14(2), 68-84. Retrieved September 13, 2017. 